\title{
Maximal Exercise Capacity in Chronic Obstructive Pulmonary Disease: A Limited Indicator of the Health Status
}

\author{
T.L. Verhage J.H. Vercoulen H.A.C. van Helvoort J.B. Peters J. Molema \\ P.N.R. Dekhuijzen Y.F. Heijdra \\ Department of Pulmonary Disease and Medical Psychology, Radboud University Nijmegen Medical Centre, \\ Nijmegen, The Netherlands
}

\section{Key Words}

Cardio-pulmonary exercise testing $\cdot$ Chronic obstructive pulmonary disease $\cdot$ Dyspnoea $\cdot$ Exercise capacity .

Health status • Nijmegen Integral Assessment Framework

\begin{abstract}
Background: Dyspnoea and diminished functional status are pivotal features of the health status (HS) in chronic obstructive pulmonary disease (COPD). However, it is still not fully understood how pulmonary function tests and cardiopulmonary exercise testing relate to these aspects. This may be due to incomplete assessment and/or deficient definitions of HS. Especially regarding peak oxygen consumption, inconsistent results have been reported. Objectives: To determine the value of maximal cycle ergometry in relation to a broad spectrum of HS aspects. Methods: 129 patients with COPD, stage II and III according to the GOLD classification, performed a cardiopulmonary exercise test. Sixteen independent sub-domains of HS were assessed according to the Nijmegen Integral Assessment Framework, covering physiological functioning, complaints, functional impairments and quality of life as main domains. $\dot{V}_{2}$ max and HS sub-domains were correlated by bivariate analysis. Results: Weak correlations of $\dot{\mathrm{V}}_{2 \max }$ with most sub-domains were found,
\end{abstract}

except for exercise capacity; the other 5 sub-domains of physiological functioning did not correlate. Between different types of exercise limitation (5 types were differentiated), no significant differences were noted in the scores of 13/16 HS sub-domains. Conclusions: $\dot{\mathrm{V}}_{2 \max }$ is indeed correlated with most aspects of $\mathrm{HS}$, except for physiological variables, but associations are weak. No single exercise limitation type is associated with specific HS problems. Thus separate assessment of all HS sub-domains is advocated to ensure adequate planning of therapeutic interventions.

Copyright $\odot 2010$ S. Karger AG, Basel

\section{Introduction}

Airflow obstruction and impaired exercise capacity are the main clinical characteristics of chronic obstructive pulmonary disease (COPD) and are measured by pulmonary function tests and by cardiopulmonary exercise testing (CPET), respectively. Hitherto, CPET is considered to be a better tool to assess overall health status (HS) than resting pulmonary function tests [1]. General theories define HS to include not merely physiological functioning, but also complaints, functional impairment and quality of life (QoL) as main domains $[2,3]$.

\section{KARGER}

Fax +41613061234 E-Mail karger@karger.ch www.karger.com
(C) 2010 S. Karger AG, Basel

0025-7931/10/0806-0453\$26.00/0

Accessible online at:

www.karger.com/res
J. Vercoulen, $\mathrm{MSc}, \mathrm{PhD}$

Radboud University Nijmegen Medical Centre

PO Box 9101

NL-6500 HB Nijmegen (The Netherlands)

Tel. +31 24685 9554, Fax +31 24685 9290, E-Mail j.vercoulen@mps.umcn.nl 
Our recent study [4] confirmed this theoretical definition of HS empirically. In that study, we developed and validated a conceptual framework of HS in COPD, the Nijmegen Integral Assessment Framework (NIAF), which shows that these 4 main domains are conceptually distinct. Moreover, we found that these main domains were subdivided into 15 relatively independent sub-domains, each representing a unique aspect of HS. In another, yet unpublished study, the sub-domain fatigue was added, thus resulting in 16 sub-domains. The definition of HS provided by the NIAF is both detailed and based on empirical observations, far more than the definitions found in the literature.

With respect to airflow limitation, we showed in a previous paper that the severity of airflow limitation classified according to the Global Initiative for Chronic Obstructive Lung Diseases (GOLD) hardly relates to complaints, functional impairment or QoL [5]. Several previous studies already provided substantial evidence for such a conclusion [6-17], yielding weak correlations between forced expiratory volume in $1 \mathrm{~s}\left(\mathrm{FEV}_{1}\right)$ and components of the other 3 domains of HS.

With respect to CPET, it is unclear whether physiological impairments are reflected by functional impairments in daily life or other aspects of HS. Similar to the correlations with airflow, exercise capacity and HS aspects correlate weakly [6-17]. Moreover, the corresponding literature lacks clear definitions of HS, QoL and health-related QoL. As a consequence, these terms are frequently used interchangeably, which is a setback in comparing the results between studies. Also, most of these studies were restricted to only one or a few aspects of HS. Only two studies in COPD evaluated exercise capacity in relation to a greater number of HS aspects, using a range of questionnaires $[12,13]$. However, both studies selected different instruments, thus hampering comparability. Also, the way of exercise testing differed in both reports. One study reported a wide range of strengths of correlation of the 6-minutes walk distance (6-MWD) with various HS aspects: dyspnoea $(r=0.35)$, measures of functional status and selfefficacy walking ( $r=0.34$ and 0.68 , respectively) [12]. The correlation between 6-MWD and the Chronic Respiratory Questionnaire total score was weak $(r=0.28)$. The other study used the disease-specific questionnaire (St. George's Respiratory Questionnaire, SGRQ) and the generic SF-36 [13]. Exercise capacity measured as peak oxygen consumption $\left(\mathrm{V}_{2} \mathrm{O}_{2}\right.$ ax $)$ on treadmill was found to correlate rather strongly with the SGRQ total score $(\mathrm{r}=0.58)$ and less with some domains of the SF-36 (general health: $r=0.48$; social functioning: $\mathrm{r}=0.58$, and mental health: $\mathrm{r}=0.53$ ).
Common to all these studies is the paucity and variability in HS aspects that were measured.

Starting from the NIAF as a much more detailed and comprehensive assessment of HS, we hypothesized that maximal exercise capacity would show less strong correlations with other physiological aspects of COPD than generally reported, and low or non-significant correlations with the other sub-domains of HS. Therefore, this study explored correlations between maximal exercise capacity performed on a cycle ergometer and the 16 subdomains composing the NIAF HS assessment. Besides $\dot{\mathrm{V}}_{2}$ max, different types of exercise limitations were also evaluated with respect to HS.

\section{Materials and Methods}

\section{Study Design}

A cross-sectional cohort of patients with COPD was selected from the outpatient departments of three different hospitals. The inclusion and exclusion criteria were published elsewhere [3]. In brief, patients were included if their COPD fell within GOLD stages II and III $\left(\mathrm{FEV}_{1} /\right.$ forced vital capacity was $<70$ and $\mathrm{FEV}_{1}$ between 30 and $80 \%$ after bronchodilation), they were current or ex-smokers, were in stable clinical condition without exacerbation in the last 6 weeks before enrolment, and did not participate in a pulmonary rehabilitation program within the last 6 months, and asthma was excluded (defined as a long history of dyspnoea attacks and reversible airflow obstruction dating from childhood, with persistent airflow obstruction later on). The study was approved by the local ethics committee.

\section{Methods}

Health Status

HS was assessed by NIAF, which provides an empirical definition of HS and covers the domains physiological functioning, complaints, functional impairment and QoL. These 4 domains of HS were found to be subdivided into 16 distinct sub-domains. In this process, factor analyses were used to identify underlying concepts in the data. The sub-domains were measured by different existing tests and instruments, and for each sub-domain, a subdomain total score (STS) was calculated. Higher scores indicate a worse clinical condition. A detailed description of the validation of the NIAF and the calculation of the STS is reported elsewhere [4]. The Appendix provides details on instruments for each subdomain.

\section{Physiological Functioning}

CPET. All subjects performed an incremental maximal CPET on a bicycle, according to the criteria of the American Thoracic Society on CPET [18]. Subjects cycled on an electrically braked cycle ergometer (Masterlab ${ }^{\circledR}$, Jaeger, Würzburg, Germany) at a pedaling rate of 60 rotations $\cdot \mathrm{min}^{-1}$ breathing room air. After unloaded pedaling for $3 \mathrm{~min}$, the workload was increased every minute by $5-20 \mathrm{~W}$. During exercise, ventilation $(\dot{\mathrm{V}} \mathrm{E}), \mathrm{V}_{2}$ and carbon dioxide production $\left(\mathrm{V} \mathrm{CO}_{2}\right)$ were measured breath by breath 
Table 1. Anthropometric, spirometric and CPET results $(\mathrm{n}=129)$

\begin{tabular}{|c|c|}
\hline Age, years & $64.5(9.2)$ \\
\hline Sex, males/females & $106 / 23(82.2 / 17.8 \%)$ \\
\hline \multicolumn{2}{|l|}{ Smoking status } \\
\hline Current smokers & $38(29.5 \%)$ \\
\hline Former smokers & $91(70.5 \%)$ \\
\hline \multicolumn{2}{|c|}{ Self-reported history of COPD ${ }^{a}$} \\
\hline$<1$ years & $15(12.3 \%)$ \\
\hline $1-10$ years & $55(45.1 \%)$ \\
\hline$>10$ years & $52(42.6 \%)$ \\
\hline $\mathrm{BMI}$ & $25.7(3.9)$ \\
\hline IVC, \%pred. & $92.3(15.0)$ \\
\hline $\mathrm{FEV}_{1}, \%$ pred. & $51.1(11.8)$ \\
\hline $\mathrm{FEV}_{1} / \mathrm{IVC}, \%$ & $42.9(10.9)$ \\
\hline RV, \%pred. & $131.3(35.1)$ \\
\hline TLC, \%pred. & $103.3(16.0)$ \\
\hline TLCO, \%pred. & $66.8(23.3)$ \\
\hline $\mathrm{PaO}_{2}$ (rest), $\mathrm{kPa}$ & $10.9(1.3)$ \\
\hline $\mathrm{PaO}_{2}, \mathrm{~mm} \mathrm{Hg}$ & $81.8(9.8)$ \\
\hline $\mathrm{PaCO}_{2}$ (rest), $\mathrm{kPa}$ & $5.2(0.5)$ \\
\hline $\mathrm{PaCO}_{2}, \mathrm{~mm} \mathrm{Hg}$ & $39(3.8)$ \\
\hline$\dot{\mathrm{V}} \mathrm{O}_{2 \max }, \%$ pred. & $71.2(18.1)$ \\
\hline \multicolumn{2}{|c|}{ Borg score at max. workload } \\
\hline Breathing effort & $5.8(2.1)$ \\
\hline Leg effort & $6.0(2.4)$ \\
\hline
\end{tabular}

Values are presented as means (SD) except for sex, smoking status and history of COPD (n). IVC = Inspiratory vital capacity; $\mathrm{RV}=$ residual volume; $\mathrm{TLC}=$ total lung capacity.

a Refers to 122 patients due to 7 missing values.

(Vmax 29; SensorMedics, Bilthoven, The Netherlands). Electrocardiography was conducted, and saturation was measured using a pulse oxymeter (Datex, Helsinki, Finland). Additionally, blood pressure was measured every 3 min during the test and Borg scores $(0-10)$ for dyspnoea and leg fatigue were obtained before and at maximal exercise. Arterial blood gasses $\left(\mathrm{PaO}_{2}, \mathrm{PaCO}_{2}\right.$, and base excess) were obtained from a cannula in the radial or brachial artery before exercise, every 3 min during exercise, at maximal exercise and $3 \mathrm{~min}$ after the end of exercise and stored in heparinized syringes (Bayer ${ }^{\circledR}$, East Walpole, Mass., USA). Predicted $\dot{\mathrm{VO}}_{2}$ was derived according to the recommendation by Wasserman [19].

Description of Exercise Limitation. An integrated approach to the interpretation of exercise data was used, with special reference to the 9 panel plots proposed by Wasserman [20]. Key parameters such as VE, heart rate (HR), blood gases and anaerobic threshold were compared to their respective predicted values. Hereby, physiological impairments that lead to exercise limitation can be determined, providing 4 main types discerned in this paper (1-4). Although there is no scientific consensus on the distinct types of exercise limitation in COPD, these descriptions are frequently used in the literature. Quantitative criteria were chosen as much in line with physiological boundaries as possible.

Exercise Capacity and Its Relevance for the Health Status
Based on the physiological data during exercise, exercise limitation of a patient was attributed to one of the following causes:

(1) Ventilatory limitation [breathing reserve (maximal voluntary ventilation - $\dot{\mathrm{VE}}$ ) of $<11$ 1/min or $<15 \%$ of predicted (\%pred.)] and/or increasing $\mathrm{PaCO}_{2}$, and/or decreasing $\mathrm{PaO}_{2}$ without signs of oxygen uptake limitation.

(2) Oxygen uptake limitation [increased alveolar-arterial oxygen pressure difference $\mathrm{P}(\mathrm{A}-\mathrm{a}) \mathrm{O}_{2} \geq 4.6 \mathrm{kPa}$ during exercise in combination with $\mathrm{PaO}_{2} \leq 8 \mathrm{kPa}$ ].

(3) Cardiocirculatory limitation, divided into cardiovascular disease or decreased physical condition (the subject reached his or her predicted maximal HR or HR reserve $<15$ beats/min) and acidosis ( $\Delta$ base excess $>8 \mathrm{mEq} / \mathrm{l}$ ) at maximal workload.

(4) Symptom limitation (no maximal exercise based on physiological data, but patient stopped because of symptoms).

(5) Combined limitations (ventilatory and cardiocirculatory limitation, or ventilatory and oxygen uptake limitation). This group was chosen if no selection between two concurrent causes could be made.

Other Physiological Measurements. Spirometry, diffusion capacity for carbon monoxide (TLCO), skeletal and respiratory muscle force and fat-free mass (FFM) were measured according to current international guidelines.

Complaints, Functional Impairment and QoL

They were determined according to NIAF. The Appendix provides details on instruments and subscales composing the NIAF.

Analysis

Correlations between $\dot{\mathrm{V}}_{2}$ max (\%pred.) and STS of the NIAF were calculated by Pearson's correlation coefficients. To test differences in STS between the distinct types of exercise limitation, ANOVA was used. A post hoc analysis to correct for multiple comparisons (Bonferroni) was applied to identify between which types significances existed. In the same manner, ANOVA and post hoc tests were carried out to test differences in $\dot{\mathrm{V}}_{2}$ max between the types of exercise limitation.

A $\mathrm{p}<0.01$ was taken as significant to avoid type I error due to multiple testing.

\section{Results}

From 361 eligible patients, 135 fulfilled the inclusion criteria. They all gave written informed consent to the study protocol. For this study, however, 6 patients had to be excluded because of interruption of their cycle ergometry test due to cardiac arrhythmias. Table 1 shows the characteristics of the 129 patients involved.

Anthropometric data together with spirometry and ergometry results of the 129 patients are displayed in table 1 . The study sample consisted mainly of elderly patients, predominantly men, with slightly raised body mass index (BMI), moderate decrease in TLCO and signs of hyperinflation. Mean resting values of $\mathrm{PaO}_{2}$ and $\mathrm{PaCO}_{2}$ were within normal limits. Mean $\dot{\mathrm{V}}_{2 \max }$ (\%pred.) was clearly below normal. 
Table 2. Correlation between $\dot{\mathrm{VO}}_{2 \text { max }}$ and the NIAF sub-domains of HS ( $\mathrm{n}=129)$

\begin{tabular}{|c|c|c|}
\hline $\begin{array}{l}\text { Correlation of sub-domains with } \\
\dot{\mathrm{V}} \mathrm{O}_{2 \max }, \% \text { pred. }\end{array}$ & $\begin{array}{l}\text { Pearson } \\
\text { correlation }\end{array}$ & $\mathrm{p}$ \\
\hline \multicolumn{3}{|l|}{ Physiological functioning } \\
\hline Airflow & -0.208 & 0.018 \\
\hline Hyperinflation & -0.070 & 0.429 \\
\hline Exercise capacity & -0.799 & $<0.001$ \\
\hline \multicolumn{3}{|l|}{ Gas exchange } \\
\hline$\Delta(\mathrm{A}-\mathrm{a}) \mathrm{DO}_{2}$ & -0.025 & 0.776 \\
\hline$\Delta \mathrm{PaCO}_{2}$ & 0.148 & 0.095 \\
\hline Muscle force & -0.193 & 0.028 \\
\hline Body composition & 0.133 & 0.134 \\
\hline \multicolumn{3}{|l|}{ Complaints } \\
\hline Subjective pulmonary complaints & -0.290 & 0.001 \\
\hline Dyspnoea emotions & -0.208 & 0.018 \\
\hline Dyspnoea expected & -0.252 & 0.004 \\
\hline Fatigue & -0.248 & 0.005 \\
\hline \multicolumn{3}{|l|}{ Functional impairment } \\
\hline Actual physical activity & -0.303 & $<0.001$ \\
\hline Behavioural impairments & -0.339 & $<0.001$ \\
\hline Subjective impairments & -0.361 & $<0.001$ \\
\hline \multicolumn{3}{|l|}{ Quality of life } \\
\hline General QoL & -0.240 & $<0.006$ \\
\hline Satisfaction health & -0.310 & $<0.001$ \\
\hline Satisfaction relations & -0.011 & 0.903 \\
\hline \multicolumn{3}{|c|}{$\begin{array}{l}\text { Sub-domains are grouped into four main domains. Negative } \\
\text { signs indicate worse scores of sub-domains with lower } \mathrm{V}_{2 \max } \\
\text { because STS were mirrored. } \Delta(\mathrm{A}-\mathrm{a}) \mathrm{DO}_{2}=\mathrm{Change} \text { in alveolar-ar- } \\
\text { terial oxygen difference during the exercise test; } \Delta \mathrm{PaCO}_{2}=\text { change } \\
\text { in arterial carbon dioxide tension during the exercise test. Sig- } \\
\text { nificant correlations are in bold. }\end{array}$} \\
\hline
\end{tabular}

As shown in table $2 \dot{\mathrm{V}}_{2 \max }$ (\%pred.) was associated with many sub-domains of HS, but the observed correlations were weak (highest $r=0.36$ for subjective impairments). With respect to the main domain physiological functioning, the correlation with the sub-domain exercise capacity was very strong, as expected. No significant correlations were found between $\dot{\mathrm{V}}_{2 \text { max }}$ and the other physiological sub-domains. With respect to the other main domains, the highest correlations were found between $\dot{\mathrm{V}}_{2 \max }$ and the three sub-domains of functional impairment (subjective impairment, behavioural impairment and actual physical activity). However, correlations were still weak.

The interpretation of causes of exercise limitation at cycle ergometry led to 5 categories (see Methods) with
Table 3. ANOVA of sub-domains of the NIAF with the type of exercise limitation as dependent variable $(n=129)$

\begin{tabular}{llr}
\hline NIAF sub-domains & F ratio & \multicolumn{1}{c}{$\mathrm{p}$} \\
\hline Physiological functioning & & \\
Airflow & 9.55 & $<\mathbf{0 . 0 0 1}$ \\
Hyperinflation & 0.85 & 0.495 \\
Exercise capacity & 9.67 & $<\mathbf{0 . 0 0 1}$ \\
Gas exchange & & \\
$\quad$ (A-a)DO ${ }_{2}$ & 9.31 & $<\mathbf{0 . 0 0 1}$ \\
$\quad \Delta$ PaCO $_{2}$ & 6.13 & $<\mathbf{0 . 0 0 1}$ \\
Muscle force & 2.56 & 0.042 \\
Body composition & 1.19 & 0.317 \\
\hline Complaints & & \\
Subjective pulmonary complaints & 2.56 & 0.042 \\
Dyspnoea emotions & 0.90 & 0.468 \\
Dyspnoea expected & 2.93 & 0.024 \\
Fatigue & 1.24 & 0.298 \\
\hline Functional impairment & & \\
Actual physical activity & 0.28 & 0.889 \\
Behavioural impairments & 2.07 & 0.089 \\
Subjective impairments & 2.62 & 0.038 \\
\hline Quality of life & & \\
General QoL & 1.82 & 0.130 \\
Satisfaction health & 2.65 & 0.036 \\
Satisfaction relations & 2.51 & 0.045 \\
\hline
\end{tabular}

$\mathrm{F}$ ratio $=$ Ratio of mean squares between groups and within groups of different types of exercise limitation. Five types were distinguished: ventilatory limited, limitation in oxygen uptake, limited by physical condition, symptom limited and combined causes. Sub-domains are grouped into four main domains. Significant correlations are in bold.

rather unequal group sizes. The ventilatory-limited group contained 54 patients, the oxygen uptake-limited group 7 patients, the cardiocirculatory-limited group 28 patients, the symptom-limited group 17 patients and the group of combined causes 23 patients.

Variation in $\dot{\mathrm{V}}_{2 \max }$ for each type of exercise limitation is shown in figure 1. $\dot{V}_{2}{ }_{2 \max }$ (\%pred.) appeared different only between the oxygen uptake-limited group (the most impaired group) and those limited by physical condition, which had the best median $\dot{\mathrm{V}}_{2 \max }$ (\%pred.).

ANOVA with exercise limitation as the dependent variable and sub-domains of the NIAF as independent variable (table 3) demonstrated some significant differences between exercise limitation within the main domain physiological functioning. This concerned airflow, 


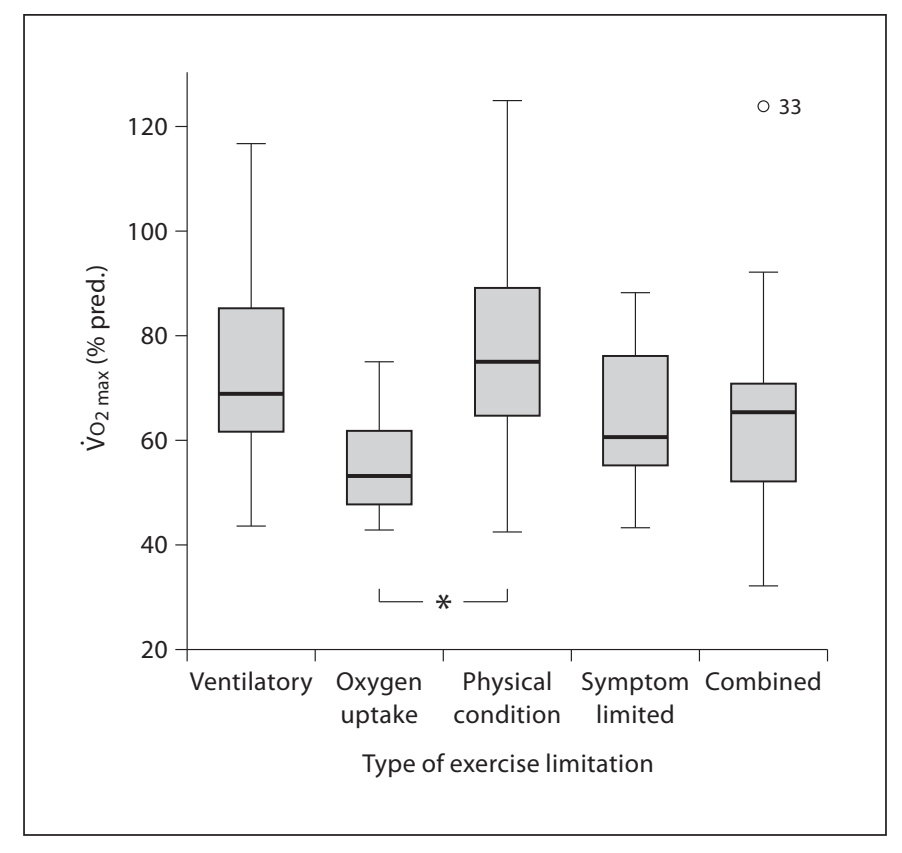

Fig. 1. Box plot representing $\dot{\mathrm{V}}_{2 \max }$ (\%pred.) in five groups with different causes of exercise limitation during cycle ergometry. Boxes define 25th and 75th percentiles with medians depicted as horizontal bar. ${ }^{*} \mathrm{p}=0.021$ (post hoc analysis). Outliers are also shown (O).

exercise capacity and change in alveolar-arterial oxygen gradient and in $\mathrm{PaCO}_{2}$ during exercise. Box plots of these sub-domains are shown in figure 2 , in which the significant between-group differences are drawn. Differences are most marked in comparisons in which the type of exercise limitation is closely linked to the sub-domain involved, like the oxygen uptake-limited group concerning change in (A - a) $\mathrm{DO}_{2}$ (fig. 2c).

No significant differences were observed in any subdomain of the other 3 main domains.

\section{Discussion}

The present study shows that maximal exercise capacity expressed by $\dot{\mathrm{O}}_{2 \max }$ is correlated with many aspects of complaints, impairments and QoL in patients with COPD, in particular with measures of functional impairment in daily life. However, it must be noted that correlations were weak. Remarkably, it was found that exercise capacity, measured during incremental bicycle ergometry, was not associated with any of the other physiological variables representing airflow limitation, hy- perinflation, gas exchange or systemic effects of COPD. Also, the physiological causes of exercise limitation derived from standard CPET did not appear to be related to problems in the different aspects of HS. These results strongly favour a clinical approach of patients with COPD in all severity stages to be assessed for their HS in a comprehensive and detailed manner (i.e. assessment of all sub-domains). This enables chest physicians to focus therapeutic efforts on the most affected (sub-)domains and in this way treatment can be tailored to the specific needs of the individual patient. Then it may be expected that patients will benefit more in their functional status and/or QoL.

Comparing our results with the current literature revealed rather good agreement, but looking in more detail, it became evident that the literature is far from unambiguous. This is mainly due to methodological problems in HS assessment. First, studies to date measure HS in many different ways selecting different instruments from the available abundance of tools. Second, current instruments measure only few aspects of HS, and, third, they do not always measure what can be expected at face value [4]. Fourth, because of the lack of clear definitions, terms as HS, health-related QoL and QoL are used interchangeably, posing further difficulty in interpretation of instruments presumed to assess those concepts [4].

NIAF provides a definition of HS that is much more detailed and more formulated in terms of empirical observations than definitions found in the literature. In addition, the NIAF integrates many existing instruments in such a way that a detailed assessment of HS is warranted.

\section{Relation of $\dot{V}_{2 \max }$ with Physiological Sub-Domains}

With respect to significant correlations between $\dot{\mathrm{V}}_{2 \max }$ and other physiological parameters, the literature provided evidence for a role of $\mathrm{FEV}_{1}$, TLCO, respiratory muscle force and FFM. However, the magnitude of those individual correlations varied greatly. Concerning $\mathrm{FEV}_{1}$, weak-moderate and even strong correlations can be found [21-24], proving that $\dot{\mathrm{O}}_{2 \text { max }}$ is not determined by a few fixed variables. This study exhibits no relationship between $\dot{\mathrm{V}}_{2 \max }$ and the sub-domain airflow, composed of $\mathrm{FEV}_{1}$ (\%pred.), $\mathrm{VE}$ (\%pred.) and maximal expiratory flow at 50\%pred., although $\mathrm{FEV}_{1}$ (\%pred.) alone did show a significant correlation ( $r=0.46$, result not shown). An effect of units cannot be ruled out as a cause of the difference in some studies. Various studies used $\mathrm{FEV}_{1}$ expressed in liters, others as percent of predicted, but mostly not both. We preferred to use $\mathrm{FEV}_{1}$ \%pred. values to eliminate variance based on height, age and sex. 

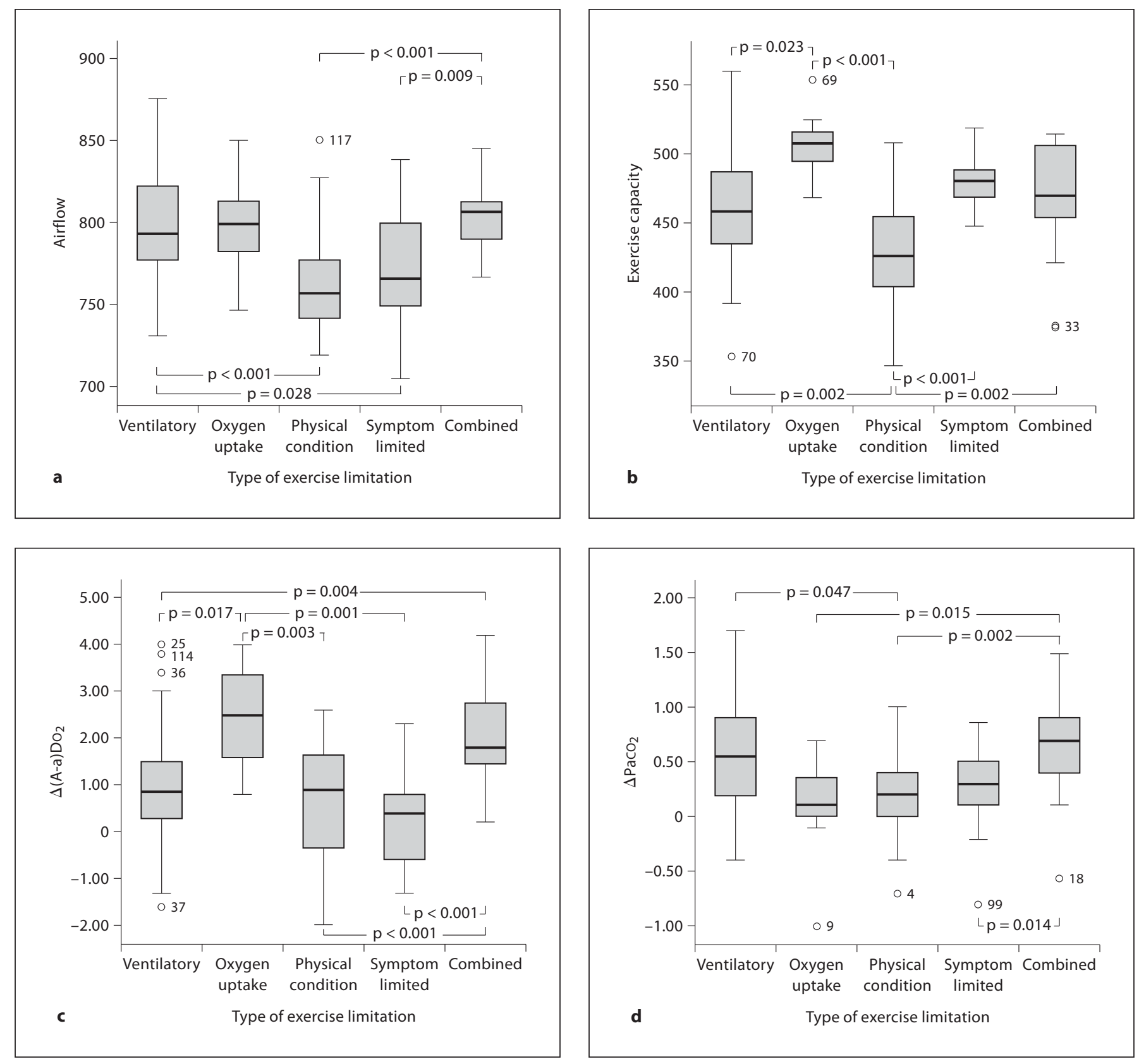

Fig. 2. STS box plots. Significant between-group differences, based on post hoc analyses, are indicated. a, b STS airflow (a) and STS exercise capacity (b) according to the type of exercise limitation. Higher scores mark worse clinical parameters. c, $\mathbf{d}$ Box plots of the NIAF sub-domain gas exchange with $\Delta(\mathrm{A}-\mathrm{a}) \mathrm{DO}_{2}$ (c) and

$\dot{\mathrm{V}}_{2 \text { max }}$ neither demonstrated a significant correlation with muscle force, nor with any of the composing parameters maximal inspiratory and expiratory pressure or leg force, \%pred. (results not shown). The lack of a significant association of the sub-domain body composition, com-

$\Delta \mathrm{PaCO}_{2}(\mathbf{d})$ during cycle ergometry $(\mathrm{kPa})$ according to the type of exercise limitation. Positive values indicate a rise in the alveolararterial oxygen gradient or $\mathrm{PaCO}_{2}$ during exercise. Outliers are also shown $(\bigcirc)$.

prising $\mathrm{BMI}$ and FFM index, with $\mathrm{V}_{2}$ max , is probably explained by the small numbers of patients with low BMI $\left(\leq 21 \mathrm{~kg} / \mathrm{m}^{2}\right)$ or low FFM index $($ men $<16$, women $<15)$ in our sample (16 and 21 , respectively). 
Exercise capacity, as it is captured in the composite NIAF sub-domain, though remotely associated with some physiological variables such as $\mathrm{FEV}_{1}$, TLCO and inspiratory muscle strength, must be considered to be a different aspect in the disease presentation of COPD, and therefore warrants separate assessment. This view is supported by two other studies that were based on principal component analysis, the method also involved in this study $[25,26]$. These studies, although not using identical variables, concluded that walking distance belonged to a separate factor than airway obstruction or spirometric variables, and hyperinflation.

\section{Relation of $\dot{V}_{2 \max }$ with Complaints}

The relation of $\dot{\mathrm{V}}_{2 \max }$ or walking distance with dyspnoea is variable according to the literature. Most studies $[10-12,16,17,27]$ used different instruments to measure dyspnoea. In two studies examining this relationship, the symptom subscale of the SGRQ, which can be considered to fall into the domain complaints, showed quite contrasting results, varying from a moderate to no significant correlation with $\dot{V}_{O_{\max }}[10,13]$. With regard to fatigue, weak correlations (up to 0.36) were reported in some studies $[10,12,17]$. As for the main domain complaints, there may be some weak correlations with $\dot{\mathrm{V}}_{2 \max }$, in agreement with our results, but the disease aspects within this domain can by far not be replaced by the outcome of a CPET.

\section{Relation of $\dot{\mathrm{V}} \mathrm{O}_{2 \max }$ with Functional Impairment}

Maximal exercise capacity can be measured either by incremental or constant loading tests. Walk tests now seem to have advantages over cycle ergometry in that they better represent someone's functional capacity and disability (the 6-MWD especially) and better respond to changes during rehabilitation programs (more particular the shuttle walk test) [28]. Nevertheless, we would not credit these tests with enough accuracy to substitute for the validated and far more detailed HS assessment of the NIAF, as is our main conclusion (see at the head of this section).

Some studies investigated the relationship between measures of exercise capacity and aspects of the domain functional impairment using for example the SGRQ subscales activity and impact or the Chronic Respiratory Questionnaire [10, 17]. Also, generic questionnaires inquiring physical functioning or accelerometer data reflecting actual daily activity were applied $[12,13]$. Overall correlations between $\dot{\mathrm{V}}_{2 \text { max }}$ and indices of functional impairment were moderate to strong $(r=0.35-0.59)$, whereas the present study only found weak correlations, the highest being $r=0.36$.

One study [12] presented data on actual daily activity measured by a multi-axis accelerometer in correlation with exercise parameters, and showed a strong correlation $(r=0.60)$. Using a similar accelerometer, we found a clearly weaker correlation of the sub-domain actual physical activity with exercise capacity $(\mathrm{r}=0.30)$. This might be explained by different ways of exercising performed in the two studies. Higher scores on the accelerometer reflect better skills in walking, not necessarily in cycling, and thus correlation with 6-MWD is likely to be stronger. We think that maximal physical capacity on a cycle ergometer accurately reflects what a person is able to, but does not predict his or her pattern of daily activities. Some patients will exceed their limits in physical capacities, others avoid most exercise in fear of severe dyspnoea or fatigue or because of a more sedentary lifestyle. Measuring this separate aspect of health status thus benefits the diagnostic work-up, because accelerometry indicates what a patient really does in daily life, $\dot{\mathrm{V}}_{2}$ max what a patient can do, and subjective impairment indicates what a patient believes he can do.

\section{Relation of $\dot{V} O_{2 \max }$ with QoL}

QoL refers to satisfaction with life [3, 29]. The NIAF sub-domain general QoL refers to satisfaction with life in general and emotional well-being reflected by mood and anxiety. As far as we are aware from searches in the literature, general QoL has rarely been investigated in relation to exercise capacity. In COPD the relation between general QoL and exercise capacity is grossly unexplored. Only one study correlated anxiety, depression, mood and psychological distress with 6-MWD, revealing no correlations [7]. Our findings regarding $\dot{\mathrm{V}}_{2 \max }$ (\%pred.), however, show weak but significant correlations with the subdomains general QoL and satisfaction health (health-related QoL). We would like to explain these two findings as follows. First satisfaction health covers physical functioning and confidence in the future. Both satisfaction health and $\dot{\mathrm{V}}_{2 \max }$ are associated with a decline in exercise capacity during the progression of COPD, thus leading to some correlation. Concerning general QoL and $\dot{\mathrm{V}}_{2 \text { max }}$, we think that some relation is probable, because both parameters are connected to the severity of COPD according to the GOLD classes. However, from the scarce data on these relationships of course no firm conclusions can be drawn. 


\section{Influence of Types of Exercise Limitations on Health Status}

From a theoretical point of view, fatigue could be more prominent in patients in whom oxygen uptake is the dominant limiting factor in comparison with ventilatory-limited patients. This is supported by clinical experience learning that rapid onset of fatigue is common in patients with interstitial lung disease, who frequently show disturbed oxygen uptake. Progressive hypoxaemia during exercise, however, invariably provokes dyspnoea in patients with COPD.

In our study no significant differences were found between the four types of exercise limitation in sub-domains of HS, except for some in the physiological functioning domain. No differences in any other sub-domain of HS were found, denying the existence of such relations that were postulated prior to the conduct of our study.

In contrast to our findings, one study studying symptoms due to pathophysiological impairments during CPET in COPD patients and healthy persons discriminated symptoms between those impaired by poor physical condition (more often leg fatigue) and those by ventilatory limitation (more often dyspnoea) [30]. However, a substantial amount of overlap existed in the Borg scores between these two groups. In addition, our study assessed dyspnoea and fatigue in quite a different way, i.e. during daily activities over a considerable time span.

\section{Conclusion}

This study is the first to evaluate the meaning of $\dot{\mathrm{V}}_{2}$ max by a large number of HS aspects, which were based on a validated conceptual framework of HS [4]. This framework measures many unique aspects of HS covering the domains physiological functioning, complaints, functional impairment and QoL. Thereby, this framework (NIAF) is to be preferred over usual methods of HS assessment.

The results of this study imply that measuring $\dot{V}_{2 \max }$ helps to quantify the maximal workload and to understand the physiological changes and limitations occurring in COPD during exercise. This is of great importance in planning pulmonary rehabilitation or preoperative evaluation. However, CPET performance poorly predicts the severity of complaints, functional impairments in daily life or QoL, since it is largely independent of these disease aspects, as proved by many low or even absent correlations. This means that in clinical practice, which also comprises rehabilitation, all main domains with their sub-domains should be assessed in order to obtain a detailed picture, because they represent unique aspects of a patient's HS. Only then HS can be improved by directing therapeutic efforts at the most affected subdomains.

\section{Acknowledgements}

We are indebted to Dr. F. van den Elshout (pulmonologist, Rijnstate Hospital, Arnhem, The Netherlands) and Dr. R. Bunnik (pulmonologist, Maas Hospital, Boxmeer, The Netherlands) for their contribution in the patient recruitment, and to the multidisciplinary Taskforce Assessment, Department of Pulmonary Rehabilitation, for their invaluable contributions to the conceptual models underlying the NIAF. The study was supported by grants from the Dutch Asthma Foundation, GlaxoSmithKline, and the Departments of Medical Psychology and Pulmonary Diseases, Radboud University Nijmegen Medical Center, Nijmegen, The Netherlands.

\section{Appendix}

A list of instruments indicating the subscales used for measuring main domains and sub-domains of the NIAF HS concept is shown

\begin{tabular}{ll} 
Main domains and sub-domains & Parameters \\
\hline $\begin{array}{l}\text { Physiological functioning } \\
\text { Airflow }\end{array}$ & $\mathrm{FEV}_{1}(\%), \mathrm{MEF}, \dot{\mathrm{V}}(\%)$ \\
Static lung volumes & $\mathrm{TLC}(\%), \mathrm{RV}(\%)$ \\
Exercise capacity & $\mathrm{VO}_{2}(\%), \mathrm{TLCO}(\%), \Delta \mathrm{BE}, \mathrm{HR}_{\max }(\%)$ \\
Gas exchange & $\Delta(\mathrm{A}-\mathrm{a}) \mathrm{DO}_{2}, \Delta \mathrm{PaCO}_{2}$ \\
Muscle force & $\mathrm{PI}_{\max }(\%), \mathrm{PE}$ max $(\%)$, leg force $(\%)$ \\
Body composition & $\mathrm{BMI}\left(\mathrm{kg} / \mathrm{m}^{2}\right), \mathrm{FFM}$ index $\left(\mathrm{kg} / \mathrm{m}^{2)}\right.$
\end{tabular}




\begin{tabular}{|c|c|c|}
\hline & Instrument & Subscale \\
\hline \multicolumn{3}{|l|}{ Complaints } \\
\hline \multirow{5}{*}{$\begin{array}{l}\text { Subjective pulmonary } \\
\text { complaints }\end{array}$} & Physical activity rating scale-dyspnoea & Global activities \\
\hline & & Global burden \\
\hline & & Specific activities \\
\hline & Dyspnoea emotions questionnaire & Dyspnoea subjective \\
\hline & QoL for respiratory illness questionnaire & Breathing problems \\
\hline \multirow[t]{3}{*}{ Dyspnoea emotions } & Dyspnoea emotions questionnaire & Frustration \\
\hline & & Mood \\
\hline & & Anxiety \\
\hline Expected dyspnoea & Physical activity rating scale-dyspnoea & Expected dyspnoea \\
\hline \multicolumn{3}{|l|}{ Functional impairment } \\
\hline Actual physical activity & Accelerometer & \\
\hline \multirow[t]{4}{*}{ Behavioural impairment } & Sickness impact profile & Body care and movements \\
\hline & & Home management \\
\hline & & Mobility \\
\hline & & Ambulation \\
\hline \multirow[t]{5}{*}{ Subjective impairment } & QoL for respiratory illness questionnaire & General activities \\
\hline & Global impairment & Social activities \\
\hline & Sickness impact profile & Total \\
\hline & & Burden \\
\hline & & Social interaction \\
\hline \multicolumn{3}{|l|}{ Quality of life } \\
\hline \multirow[t]{3}{*}{ General QoL } & Satisfaction with life scale & Total \\
\hline & Symptom checklist & Anxiety \\
\hline & Beck depression inventory & Primary care \\
\hline \multicolumn{3}{|l|}{ Satisfaction } \\
\hline \multirow[t]{2}{*}{ Health } & Physical & \\
\hline & Future & \\
\hline \multirow[t]{2}{*}{ Relations } & Spouse & \\
\hline & Social & \\
\hline
\end{tabular}

Main domains are shown in italics. $\triangle \mathrm{BE}=$ Change in base excess between start and end of maximal cardiopulmonary exercise test; $\mathrm{MEF}=$ maximal expiratory flow at $50 \%$ pred.; $\mathrm{PI}_{\max }=$ maximal inspiratory pressure; $\mathrm{PE}_{\max }=$ maximal expiratory pressure.

\section{References}

1 Piepoli MF: Exercise tolerance measurements in pulmonary vascular diseases and chronic heart failure. Respiration 2009;77: 241-251.

2 Spilker B, Revicki DA: Taxonomy of quality of life; Spilker B (ed): Quality of Life and Pharmaeconomics in Clinical Trials, ed 2. Philadelphia, Lippincott-Raven, 1996, pp 25-31.

$\checkmark 3$ Wilson IB, Cleary PD: Linking clinical variables with health-related quality of life. A conceptual model of patient outcomes. JAMA 1995;273:59-65.

$\checkmark 4$ Vercoulen JH, Daudey L, Molema J, Vos PJ, Peters JB, Top M, et al. An integral assessment framework of health status in chronic obstructive pulmonary disease (COPD). Int J Behav Med 2008;15:263-279.
5 Verhage TL, Heijdra YF, Molema J, Daudey L, Dekhuijzen PNR, Vercoulen JH: Adequate patient characterization in COPD. Reasons to go beyond GOLD classification. Open Respir Med J 2009;3:1-9.

6 Wijkstra PJ, Van Altena R, Kraan J, Otten V, Postma DS, Koeter GH: Quality of life in patients with chronic obstructive pulmonary disease improves after rehabilitation at home. Eur Respir J 1994;7:269-273.

7 Borak J, Chodosowska E, Matuszewski A, Zielinski J: Emotional status does not alter exercise tolerance in patients with chronic obstructive pulmonary disease. Eur Respir J 1998; 12:370-373.

8 Jones PW: Impact of lower respiratory tract infections on health status. Semin Respir Crit Care Med 2000;21:107-111.
-9 Oga T, Nishimura K, Tsukino M, Hajiro T, Ikeda A, Mishima M: Relationship between different indices of exercise capacity and clinical measures in patients with chronic obstructive pulmonary disease. Heart Lung 2002;31:374-381.

10 Hajiro T, Nishimura K, Tsukino M, Ikeda A, Koyama H, Izumi T: Comparison of discriminative properties among disease-specific questionnaires for measuring healthrelated quality of life in patients with chronic obstructive pulmonary disease. Am J Respir Crit Care Med 1998;157:785-790.

$>11$ Stavem K, Boe J, Erikssen J: Health status, dyspnea, lung function and exercise capacity in patients with chronic obstructive pulmonary disease. Int J Tuberc Lung Dis 1999;3: 920-926. 
-12 Belza B, Steele BG, Hunziker J, Lakshminaryan S, Holt L, Buchner DM: Correlates of physical activity in chronic obstructive pulmonary disease. Nurs Res 2001;50:195-202.

-13 Dowson LJ, Newall C, Guest PJ, Hill SL, Stockley RA: Exercise capacity predicts health status in $\alpha_{1}$-antitrypsin deficiency. Am J Respir Crit Care Med 2001;163:936941.

- 14 O'Leary CJ, Wilson CB, Hansell DM, Cole PJ, Wilson R, Jones PW: Relationship between psychological well-being and lung health status in patients with bronchiectasis. Respir Med 2002;96:686-692.

15 Katz PP, Eisner MD, Yelin EH, Trupin L, Earnest G, Balmes J, et al: Functioning and psychological status among individuals with COPD. Qual Life Res 2005;14:1835-1843.

-16 Oga T, Nishimura K, Tsukino M, Hajiro T, Mishima M: Dyspnoea with activities of daily living versus peak dyspnoea during exercise in male patients with COPD. Respir Med 2006;100:965-971.

17 Berry MJ, Adair NE, Rejeski WJ: Use of peak oxygen consumption in predicting physical function and quality of life in COPD patients. Chest 2006;129:1516-1522.
18 ATS/ACCP Statement on cardiopulmonary exercise testing. Am J Respir Crit Care Med 2003;167:211-277.

19 Wasserman K: Principles of Exercise Testing and Interpretation, ed 4. Philadelphia, Lippincott Williams \& Wilkins, 2005.

20 Wasserman K: Diagnosing cardiovascular and lung pathophysiology from exercise gas exchange. Chest 1997;112:1091-1101.

21 Baarends EM, Schols AM, Mostert R, Wouters EF: Peak exercise response in relation to tissue depletion in patients with chronic obstructive pulmonary disease. Eur Respir J 1997;10:2807-2813.

22 Heijdra YF, Pinto-Plata V, Frants R, Rassulo J, Kenney L, Celli BR: Muscle strength and exercise kinetics in COPD patients with a normal fat-free mass index are comparable to control subjects. Chest 2003;124:75-82.

23 Wijkstra PJ, TenVergert EM, van der Mark TW, Postma DS, Van Altena R, Kraan J, et al: Relation of lung function, maximal inspiratory pressure, dyspnoea, and quality of life with exercise capacity in patients with chronic obstructive pulmonary disease. Thorax 1994;49:468-472.

24 LoRusso TJ, Belman MJ, Elashoff JD, Koerner SK: Prediction of maximal exercise capacity in obstructive and restrictive pulmonary disease. Chest 1993;104:1748-1754.
25 Wegner RE, Jorres RA, Kirsten DK, Magnussen H: Factor analysis of exercise capacity, dyspnoea ratings and lung function in patients with severe COPD. Eur Respir J 1994; 7:725-729.

-26 Celli BR, Calverley PM, Rennard SI, Wouters EF, Agusti A, Anthonisen N, et al: Proposal for a multidimensional staging system for chronic obstructive pulmonary disease. Respir Med 2005;99:1546-1554.

27 Hajiro T, Nishimura K, Tsukino M, Ikeda A, Oga T, Izumi T: A comparison of the level of dyspnea vs disease severity in indicating the health-related quality of life of patients with COPD. Chest 1999;116:1632-1637.

28 Clini EM, Crisafulli E: Exercise capacity as a pulmonary rehabilitation outcome. Respiration 2009;77:121-128.

29 Bowling A: Measuring Disease: A Review of Disease-Specific Quality of Life Measurement Scales, ed 2. Buckingham, Open University Press, 2001, pp 1-22.

30 Killian KJ, Leblanc P, Martin DH, Summers E, Jones NL, Campbell EJ: Exercise capacity and ventilatory, circulatory, and symptom limitation in patients with chronic airflow limitation. Am Rev Respir Dis 1992;146: 935-940. 